\title{
Crystallization and demineralization phenomena in stabilized white mold cheese
}

\author{
Gil F. Tansman, ${ }^{* 1}$ Paul S. Kindstedt, ${ }^{*}$ and John M. Hughes $†$ \\ *Department of Nutrition and Food Sciences, and \\ †Department of Geology, University of Vermont, Burlington 05405
}

\section{ABSTRACT}

Stabilized white mold cheese is a commercially important variant of traditional white mold cheese (sometimes called bloomy rind cheese) that has an extended shelf life compared with the traditional permutation. The objectives of this observational study were to document mineral element movements and the development of a $\mathrm{pH}$ gradient in stabilized white mold cheese, and to use novel crystallographic techniques to identify crystals that form in the rind of this cheese. Cheeses from 3 separate batches were collected from a commercial supplier at d 1, 4, 10, 14, and 18 of aging and analyzed in a randomized block design. Samples from the center and rind of each cheese were analyzed for calcium, magnesium, phosphorus, sodium, and moisture content. The effect of location within the cheese wheel was significant for all effects, whereas the effect of aging time was significant for all effects except sodium content. The interaction between location within the cheese and aging time was significant for all effects. Using powder x-ray diffractometry, the crystals that formed in the rind during aging were identified as brushite $\left(\mathrm{CaHPO}_{4} \cdot 2 \mathrm{H}_{2} \mathrm{O}\right)$. The accumulation of mineral elements in the rind resulted in a substantial decrease in calcium, magnesium, and phosphorus in the center. After $18 \mathrm{~d}$, calcium, magnesium, and phosphorus in the center had decreased by $26.4,14.8$, and $12.1 \%$, respectively, compared with the first day of aging. The observations in the present study represent the first definitive identification of crystals in the rind of a white mold cheese. The use of novel crystallographic techniques in the present study lays the groundwork for the use of this technology in future investigations of mineral element diffusion phenomena in surface-ripened cheese.

Key words: crystal, brushite, stabilized, white mold cheese

Received November 5, 2016.

Accepted March 29, 2017.

${ }^{1}$ Corresponding author: gtansman@uvm.edu

\section{INTRODUCTION}

Texture development in traditional soft, surfaceripened white mold cheese is a complex process that involves biological and chemical factors. During aging, these cheeses develop radially, from the rind to the center, from an acidic chalky curd to a soft, viscous semisolid. An intricate framework that describes the mechanism of curd softening has developed over the past 4 decades. This framework involves several interconnected factors that affect casein solubilization and hydration. The 3 main processes that lead to cheese softening are elevated $\mathrm{pH}$, demineralization of calcium, and proteolysis (Lucey and Fox, 1993).

Some proteolytic activity can be attributed to proteases released by the surface mold; however, these proteases have limited mobility in the cheese and are only significant near the surface (Noomen, 1983). Proteolytic activity in the body of surface-ripened cheese has been attributed to plasmin and residual rennet (Karahadian and Lindsay, 1987), which, on account of their distribution throughout the cheese, cannot explain the radial ripening pattern that is characteristic of this class of cheese.

A surface-to-center $\mathrm{pH}$ gradient that develops as a result of surface mold activity is closely linked to the radial development of texture in surface-ripened cheese (Vassal et al., 1986). The surface mold consumes lactic acid as an energy and carbon source, and in doing so raises the $\mathrm{pH}$ of the curd; the mold also metabolizes the cheese proteins near the surface as a nitrogen source and releases ammonia, which also contributes to alkalinization (Amrane and Prigent, 2008). In general, at a $\mathrm{pH}$ close to 4.6, the isoelectric point of casein, cheese texture is short and casein proteins are compact (Lawrence et al., 1987). Fresh traditional white mold cheese is acidic, crumbly, and lacks the viscous texture of fully ripened white mold cheese. As the $\mathrm{pH}$ rises, on account of the surface mold activity, the texture softens and becomes semisolid (Noomen, 1983). The change in texture, however, is confounded by the amount of calcium in the curd and a pH-dependent ion diffusion phenomenon (Le Graet and Brule, 1988). 
In traditional white mold cheese, minerals diffuse from the body of the cheese and collect in an unknown form under the rind (Le Graet et al., 1983; Brooker, 1987). This diffusion mechanism is technologically important because as aging progresses, the amount of calcium phosphate in the center of the curd diminishes (Le Graet and Brule, 1988). Calcium phosphate removal is important for the development of white mold cheese texture because at diminished calcium phosphate concentrations the swelling of cheese proteins increases (Lucey and Fox, 1993). Ion diffusion occurs because crystals precipitate in the rind at high $\mathrm{pH}$, which causes a reduction in the local solubility of mineral elements. As a result, ions diffuse from the center of the cheese, where the solubility is higher, toward the rind, where they are deposited into the crystals as the crystals nucleate and grow (Le Graet et al., 1983; Le Graet and Brule, 1988; Gaucheron et al., 1999).

Ratios of calcium to phosphorus in the cheese rind have repeatedly been used to investigate the mechanism of ion diffusion (Metche and Fanni, 1978; Le Graet et al., 1983; Brooker, 1987; Boutrou et al., 1999; Gaucheron et al., 1999; Amrane and Prigent, 2008). These measurements have generated values ranging from 0.86 (Boutrou et al., 1999) to 2 (Gaucheron et al., 1999), which suggests that crystal phases with various stoichiometries may form in the rinds of different cheeses. Some authors have attributed their calcium-tophosphorus ratios to different crystal phases, including dicalcium phosphate (Amrane and Prigent, 2008), hydroxylapatite (Amrane and Prigent, 2008), tricalcium phosphate (Le Graet et al., 1983; Boutrou et al., 1999; Gaucheron et al., 1999), and magnesium phosphate (Boutrou et al., 1999). It is possible that all of these phases form in different cheeses or at different stages of ripening as a result of varying levels of alkalinity, but it is impossible to make a definitive conclusion without having used a crystallographic technique. Several authors have acknowledged the speculative nature of using the calcium-to-phosphorus ratio, suggesting that conclusive identification of the crystal phases with other techniques, such as x-ray diffraction, would be beneficial (Boutrou et al., 1999; Gaucheron et al., 1999; Amrane and Prigent, 2008).

In the present study, a stabilized-style variant of white mold cheeses was used as the experimental subject. This cheese is similar to traditional Camembert-style cheeses investigated by many of the aforementioned investigators, but has some important differences. Stabilized white mold cheese has a higher initial $\mathrm{pH}$ (Lawrence et al., 1987), which results in a much higher level of mineral element retention in the fresh curd. Due to the very different initial $\mathrm{pH}$ and mineral element content, we propose that a detailed characterization of this type of cheese would be an interesting addition to the literature. Preliminary observation in our laboratory noted that a limited but nontrivial $\mathrm{pH}$ gradient develops in this cheese, which raised the possibility that crystallization and demineralization could be factors in the ripening of stabilized white mold cheese.

The primary goal of the present study was to determine the extent of the $\mathrm{pH}$ gradient that develops in a stabilized white mold cheese and to determine if this gradient results in crystallization and demineralization phenomena, as it does in traditional white mold cheese. Novel techniques were employed to observe the onset of crystallization and to identify the crystal phases in the rind to illuminate the chemical conditions that facilitate crystallization and mineral diffusion.

\section{MATERIALS AND METHODS}

\section{Cheese Manufacture}

Cheeses were obtained from The Cellars at Jasper Hill (Greensboro, VT; hereafter referred to as The Cellars). Cheeses were manufactured from nonstandardized pasteurized milk produced at Jasper Hill Farm using a stabilized procedure approximately similar to that described in Kosikowski and Mistry (1997). The milk was inoculated with cultures that are proprietary, and therefore the specific cultures are not included in this description. The vat was drained at $\mathrm{pH} 6.1$ and molded into wheels with a $7.5 \mathrm{~cm}$ diameter and $3 \mathrm{~cm}$ height. The wheels were demolded at a $\mathrm{pH}$ of 5.15 and dry salted to a target salt-in-moisture of 2.4 to $2.6 \%$. Final cheese moisture on d 0 was 50 to $52 \%$. Wheels were kept on wire racks in a preaging room at $16^{\circ} \mathrm{C}$ for $3 \mathrm{~d}$ and then transferred to an atmospherically controlled aging vault with temperatures ranging from 11 to $12^{\circ} \mathrm{C}$ and a relative humidity of 94 to $96 \%$.

\section{Cheese Sampling}

Cheeses were sampled on $\mathrm{d} 1,4,7,10,14$, and 18. This sampling schedule was selected because it resembled the sampling schedule of Le Graet et al. (1983), although it was offset by $1 \mathrm{~d}$ because, in the present study, cheeses were not available for sampling on d 0 , which was the day of manufacture. The cheeses were wrapped in cheese paper and transported to the Department of Nutrition and Food Sciences at the University of Vermont in an insulated cooler with ice packs. Two wheels were collected from The Cellars on d 1, 4, 7, and 10. Four wheels were collected on d 14, which was the last day of cave-aging and the first day of packaging and cold storage. Two of the wheels collected on d 14 were used for analysis on d 14; the additional 2 
wheels were stored in an incubator at $4.5^{\circ} \mathrm{C}$ until d 18 , thereby simulating the cold storage conditions used in the manufacturing facility. The entire experiment was replicated 3 times using 3 different batches of cheese produced on different days 1 wk apart.

\section{Cheese Preparation for Mineral Analysis}

An illustration of the sampling scheme is found in Figure 1. The cheeses were precisely segmented with a wire cutter to remove a 2 -cm wide section along the diameter of the cheese. The center portion was laterally bisected to yield 2 pieces of cheese with dimensions measuring roughly $7.5 \times 2 \times 3 \mathrm{~cm}$ (length $\times$ width $\times$ height). The remainder of the wheel was set aside for $\mathrm{pH}$ analysis, microscopic observation, and powder x-ray diffractometry (PXRD). A small wire cutter was used to remove approximately $3 \mathrm{~mm}$ from each end of one of the $7.5 \times 2 \times 3 \mathrm{~cm}$ cheese portions, and the 3 -mm thick samples were trimmed to $1 \mathrm{~cm}$ in height so as to leave only the middle portion of the sample. This sampling procedure yielded 2 samples with dimensions measuring $20 \times 10 \times 3 \mathrm{~mm}$; 1 sample represented the approximate center of the wheel and the other represented a composite sample of the fungal rind and underlying cheese from the outer rim of the wheel. Center and rind samples were placed in preweighed ceramic drying dishes and weighed. The dishes were then placed in a draft oven at $100^{\circ} \mathrm{C}$ for $12 \mathrm{~h}$, which was found to dry the samples to a constant weight.

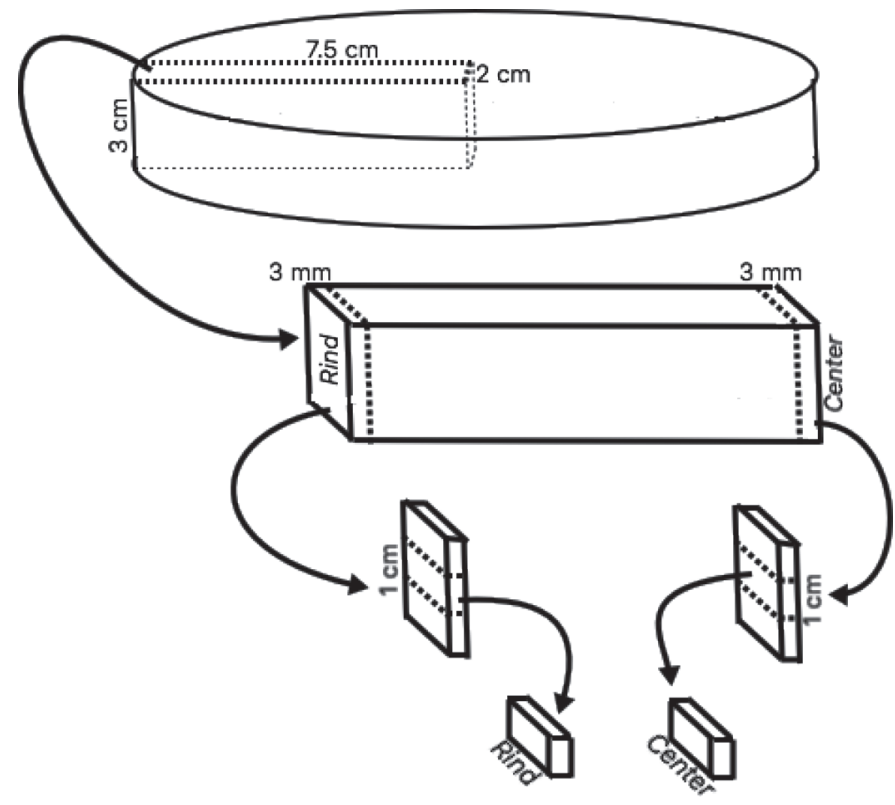

Figure 1. Illustration of the sampling scheme used for quantitative measurement of calcium, phosphorus, magnesium, and sodium content in rind and center locations.
The dried samples were removed from the oven, cooled for several minutes, and reweighed to calculate the percent moisture. The dishes were then placed in a muffle furnace at $600^{\circ} \mathrm{C}$ for $12 \mathrm{~h}$ to completely vaporize the organic material until all that remained was a small mass of acid-soluble inorganic material. Several milliliters of deionized water and $0.5 \mathrm{~mL}$ of reagent-grade concentrated sulfuric acid (Fisher Scientific, Pittsburgh, PA) were added to the dishes. The dishes were heated on a laboratory stove to completely dissolve the material, and the solutions were quantitatively transferred to 50-mL volumetric flasks, cooled to room temperature, and brought up to volume.

\section{Mineral Analysis}

Aliquots of the dissolved ash were analyzed for calcium, magnesium, phosphorus, and sodium by inductively coupled plasma-optical emission spectrometry (Optima 3000DV, Perkin Elmer Corp., Norwalk, CT). Calibration standards were prepared according to standard guidelines (EPA, 2012) to cover the range of concentrations in the sample set. Four-point calibrations (plus a calibration blank) were used for inductively coupled plasma analysis. Continuing calibration verification samples, prepared from an independent source, were used to check the calibration periodically. Concentrations of minerals were calculated on a cheese dry weight basis.

\section{pH Measurements}

A segment of cheese, left over from the sectioning of the wheel, was used in the measurement of $\mathrm{pH}$ at the rind and at the approximate center. A spear-tip $\mathrm{pH}$ electrode (Thomas Scientific, Swedesboro, NJ) was used for these measurements. The probe was inserted as close to the surface of the rind as possible without breaking through the rind and a reading was taken at the approximate center of the wheel. Readings were allowed to stabilize for 1 min before recording.

\section{Microscopy and Powder X-Ray Diffraction}

Samples were collected from the leftover cheese for microscopic observation and PXRD. Samples were removed from the approximate center and from the top $3 \mathrm{~mm}$ of the cheese with a metal spatula. The samples were smeared to nearly translucent thickness on a glass microscope slide using a metal spatula. Micrographs were captured using a Nikon E200POL petrographic microscope with a rotating stage (Nikon Corporation, Tokyo, Japan) and a SPOT Idea 1.3-megapixel color camera (SPOT Imaging Solutions, Sterling Heights, 
MI). When the polarizers were crossed, particles that were illuminated and displayed uniform extinction were identified as crystals.

For PXRD analysis, cheese samples from the approximate center and rind were loaded onto glass diffraction slides and data were collected on a MiniFlex II powder x-ray diffractometer (Rigaku, The Woodlands, TX) according to the method that we previously employed to investigate calcium lactate on Cheddar (Tansman et al., 2014). The method in the present experiment was similar, except that the samples were not dried and defatted with acetone. Diffractograms were generated at a speed of $2^{\circ} 2 \theta / \mathrm{min}$ between $5^{\circ} 2 \theta$ and $50^{\circ} 2 \theta(2 \theta$ represents the angle formed between the x-ray source, diffraction slide, and x-ray detector).

Due to the large amorphous hump that resulted from the noncrystalline mass of the samples in the present study, the software had difficulty differentiating the background from diffraction peaks because it could not accurately identify the background pattern. However, we established that the pattern generated from d-1 samples (before any crystals had formed) was apparent in diffractograms throughout the sampling timeframe and thus served as the universal background pattern. Peaks that emerged from the characteristic amorphous pattern in diffractograms collected after d 1 were manually identified as diffraction peaks. This method was beyond the capabilities of the automated functions in the software and may reflect the fact that typical diffraction samples, such as geological specimens, rarely contain as high a mass fraction of noncrystalline material as the samples in the present study.

To initially find a matching reference diffraction pattern, a literature search was conducted to compile a list of crystal phases that have been mentioned in the cheese literature. These phases included crystals that had been directly observed in cheeses, such as Cheddar and Gouda, as well as phases that were mentioned in the literature as possible candidates for the identity of crystals in the rind of white mold cheese. Reference diffraction patterns from the International Center for Diffraction Data (ICDD) database that corresponded to the phases on the list were compared with diffraction patterns from d-18 diffractograms and eliminated from the list if any of the main peaks in the reference pattern were missing from the experimental diffractograms. Once a good match was found, the reference pattern for the selected phase was compared with each experimental diffractogram to determine if the reference pattern accounted for all the diffraction peaks that appeared above the characteristic d-1 background pattern, with the absence of additional peaks indicating that the reference pattern was the only pattern in the experimental diffractogram within the sensitivity of the instrument.

\section{Statistical Analysis}

The experiment was conducted as a 3-factor randomized block design with batches representing blocks and 7 sampling points per batch. Data for $\mathrm{pH}$, selected mineral elements on a dry weight basis, moisture content, and salt-in-moisture were analyzed in the statistical package JMP Pro 12.0.0 (SAS Institute Inc., Cary, NC).

\section{RESULTS}

Summary statistics for $\mathrm{pH}$, selected mineral elements on a dry weight basis, moisture content, and salt-inmoisture are presented in Table 1 . The summary data in Table 1 demonstrate that all main and interaction effects measured for $\mathrm{pH}$, calcium, phosphorus, magnesium, and moisture content were significant. Batch and day of aging effects were not significant for sodium and salt-in-moisture, although sampling location and the interaction between sampling location and day of aging were. Notably, the interaction between day of aging and sampling location was highly significant for all variables.

Table 1. Mean squares, probabilities (in parentheses), and degrees of freedom for $\mathrm{pH}$, selected mineral elements on a dry weight basis, moisture content, and salt-in-moisture during $18 \mathrm{~d}$ of aging $\left(16^{\circ} \mathrm{C}\right.$ from d 1 to $4,11-12^{\circ} \mathrm{C}$ from d 4 to 14 , and $5^{\circ} \mathrm{C}$ from $\mathrm{d} 14$ to 18$)$

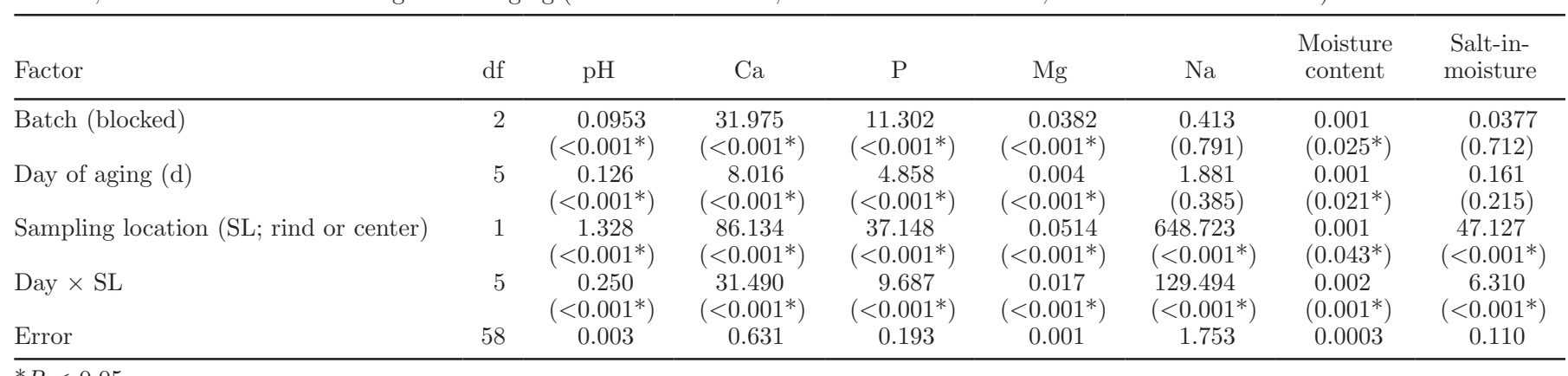

$* P<0.05$ 


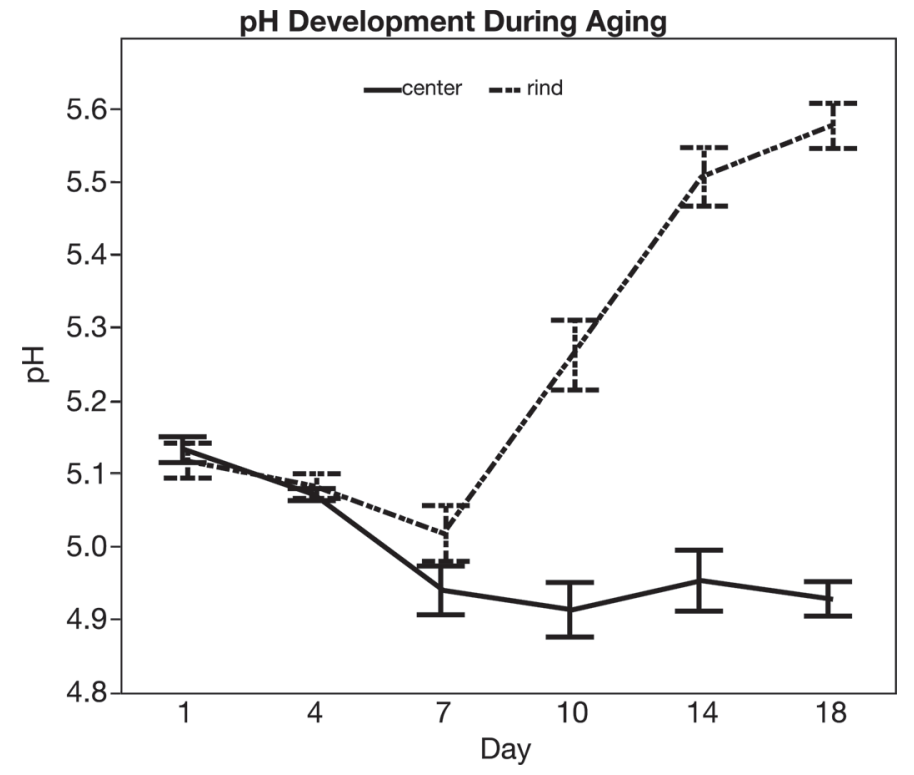

Figure 2. Average $\mathrm{pH}$ values of rind and center sampling locations during aging. Error bars represent SE from all 3 batches and duplicate cheeses on each sampling day.

Graphical representation of $\mathrm{pH}$ development during aging (Figure 2) demonstrates that as aging progressed, the $\mathrm{pH}$ of the rind and center, having been nearly identical at $\mathrm{d} 1$, diverged so that by $\mathrm{d} 18$ the $\mathrm{pH}$ of the rind was approximately $0.7 \mathrm{pH}$ units higher than the center. Most of this change was due to increased rind $\mathrm{pH}$, although a nontrivial decrease also occurred in center $\mathrm{pH}$. Rind $\mathrm{pH}$ did not rise until d 10, and even decreased slightly, along with the center $\mathrm{pH}$, until $\mathrm{d} 7$.

The elevated rind $\mathrm{pH}$ after $\mathrm{d} 7$ was accompanied by increased concentrations of calcium (Figure 3), phosphorus (Figure 4), and magnesium (Figure 5) in the rind. Increases in rind $\mathrm{pH}$, rind calcium, rind phosphorus, and rind magnesium were closely correlated according to the correlation coefficients for those variables (Table 2 ), with the largest increases of all 4 variables occurring between $\mathrm{d} 7$ and 14 . As calcium, phosphorus, and magnesium accumulated in the rind, the concentration of these elements in the center concurrently diminished.

The concentrations of sodium in the rind and center were also recorded over the aging timeframe (Figure 6), but appeared to be independent of changes in rind $\mathrm{pH}$, in contrast to the other mineral elements. On a dry weight basis, the concentrations of sodium in the center and rind appeared to converge by the end of the experimental timeframe. The changes in sodium content in the center and rind represent the inward diffusion of salt, which is applied to the surface of new cheese wheels after demolding. Salt-in-moisture (data not shown) appeared to develop very similarly to sodium on a dry weight basis, although the salt-in-moisture

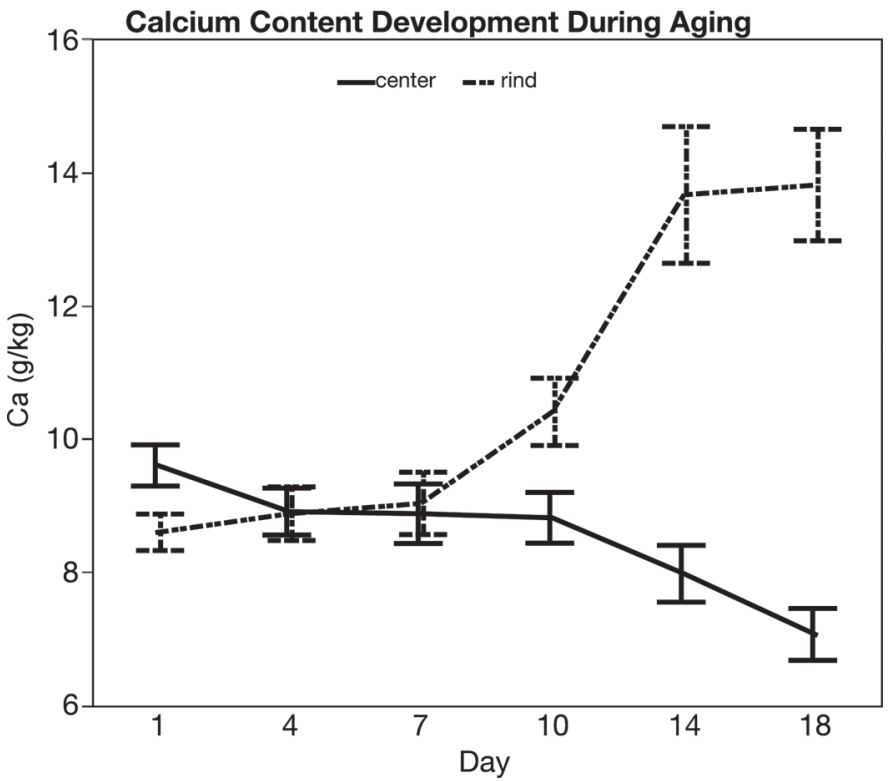

Figure 3. Average calcium concentrations of rind and center sampling locations during aging on a dry weight basis (grams of calcium per kilogram of dry cheese). Error bars represent SE from all 3 batches and duplicate cheeses on each sampling day.

content of the center and rind did not fully converge by the end of the experiment. Nonetheless, the mean salt-in-moisture of the center by d 18 was 2.49 , which is within the target salt-in-moisture as reported by The Cellars.



Figure 4. Average phosphorus concentrations of rind and center sampling locations during aging on a dry weight basis (grams of phosphorus per kilogram of dry cheese). Error bars represent SE from all 3 batches and duplicate cheeses on each sampling day. 


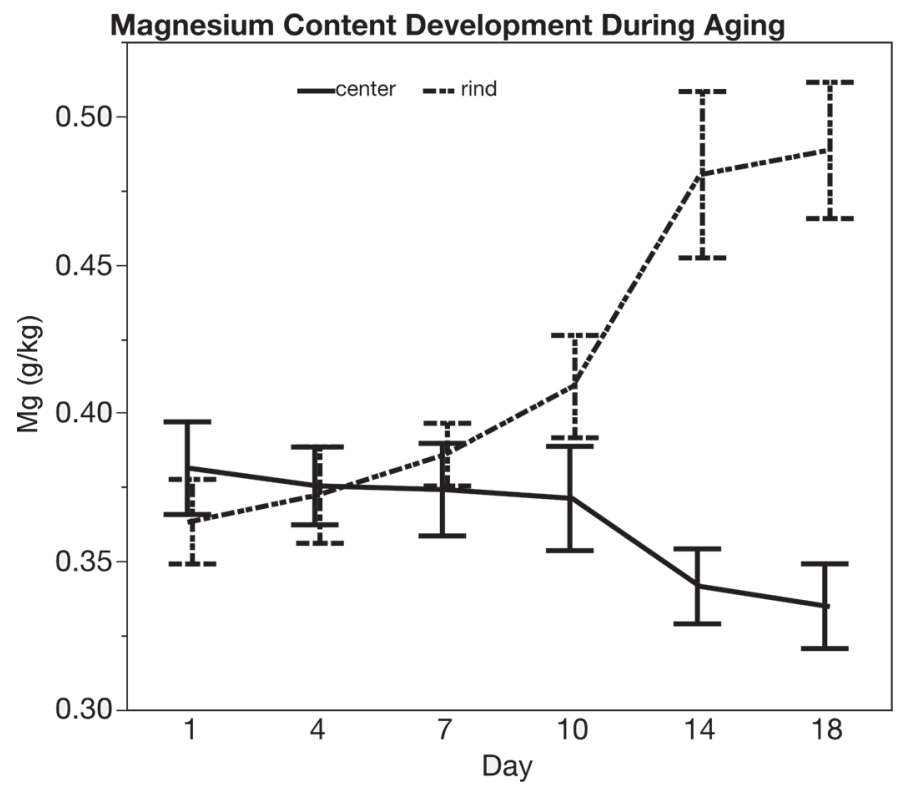

Figure 5. Average magnesium concentrations of rind and center sampling locations during aging on a dry weight basis (grams of magnesium per kilogram of dry cheese). Error bars represent SE from all 3 batches and duplicate cheeses on each sampling day.

Moisture contents of the center and rind diverged over the course of aging, with the moisture content at the center remaining fairly stable and the moisture content of the rind diminishing by several percentage points by the end of the observation period (Figure 7). The decreased moisture content in the rind was likely a result of evaporative moisture loss, which appeared to be a localized effect that did not affect the moisture content in the center.

Diffractograms of rind samples from d 1 (Figure 8A) and 4 (data not shown) did not show any evidence of crystal growth, but consistently displayed a characteristic amorphous spectrum that was interpreted as the baseline for the cheese matrix, as described in the Materials and Methods. Diffractograms from center samples throughout the experiment displayed the characteristic background spectrum, devoid of any evidence of crystal growth (data not shown). All diffractograms of rind samples starting on d 10 showed evidence of crystal growth (Figure 8B) in the form of distinct peaks

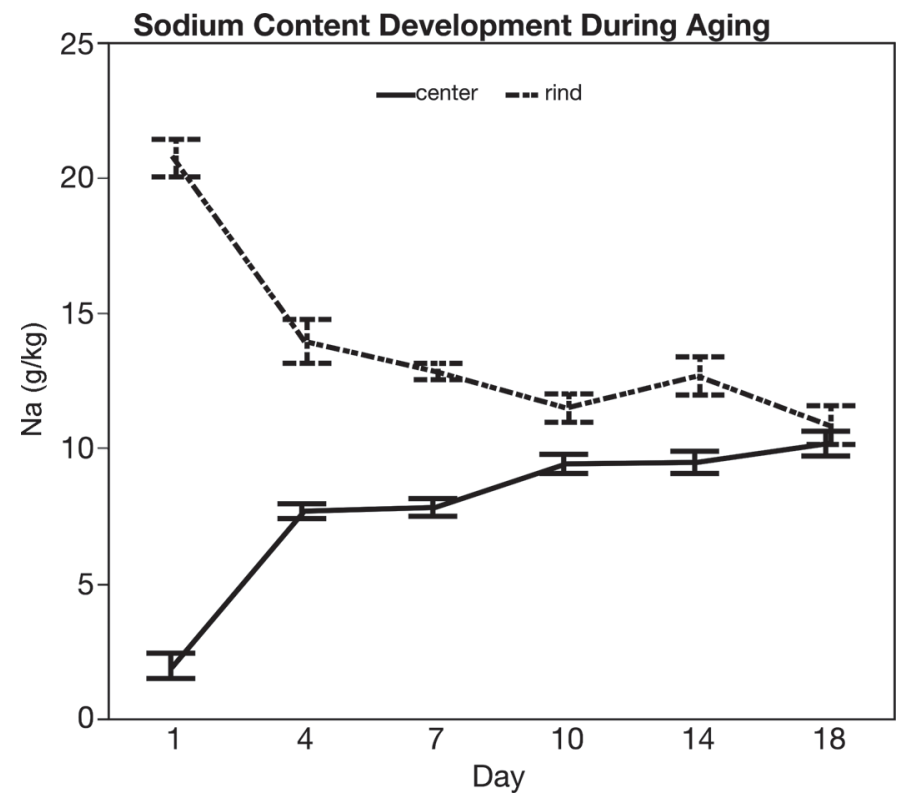

Figure 6. Average sodium concentrations of rind and center sampling locations during aging on a dry weight basis (grams of sodium per kilogram of dry cheese). Error bars represent SE from all 3 batches and duplicate cheeses on each sampling day.

along the background spectrum; these diffractograms displayed the same set of peaks with roughly the same relative intensity between peaks. Some of the d- 7 rind diffractograms displayed peaks, although the peaks were exceedingly small and only peaked at approximately $12^{\circ} 2 \theta$ and $30^{\circ} 2 \theta$; these corresponded to the largest peaks in rind diffractograms from d 10 and could be distinguished from the background (data not shown).

When rind diffractograms displaying peaks were compared with known diffraction patterns from the ICDD database, the peaks matched the reference pattern for brushite $\left(\mathrm{CaHPO}_{4} \cdot 2 \mathrm{H}_{2} \mathrm{O}\right.$, ICDD card \#01-075-4365), which is represented by the vertical bars in Figure 8B and C. Figures of merit (FOM), which are values produced by PDXL to determine the degree of fit of a reference card to a diffractogram, are presented with d 10 and 18 diffractograms in Figure 8 to indicate the degree of fit. As demonstrated in our work with calcium lactate enantiomeric variants (Tansman et al., 2014), a FOM of 1 or less indicates a very good fit. In the

Table 2. Matrix of correlation coefficients for rind $\mathrm{pH}$ and concentrations of selected mineral elements in the rind on a dry weight basis

\begin{tabular}{lcccc}
\hline Item & $\mathrm{pH}$ & $\mathrm{Ca}$ & $\mathrm{P}$ & $\mathrm{Mg}$ \\
\hline $\mathrm{pH}$ & 1.0000 & 0.8581 & 0.8839 & 0.7914 \\
$\mathrm{Ca}$ & & 1.0000 & 0.9360 & 0.8628 \\
$\mathrm{P}$ & & 1.0000 & 0.9355 \\
$\mathrm{Mg}$ & & & & 1.0000 \\
\hline
\end{tabular}


present experiment, d-10 rind diffractograms generally had FOM around 1 when fitted to ICDD card \# 01-075-4365. By d 18, rind diffractograms fitted to the same reference card had FOM well below 1, indicating that brushite was a very good fit.

Diffractograms of rind samples from d 14 and 18 showed progressively larger brushite peaks (Figure 8C), which can be interpreted as an increase in the quantity of brushite in the samples. The increased intensity of diffraction peaks above the baseline probably contributed to the reduced FOM as aging progressed. None of the diffractograms displayed peaks other than those attributable to brushite or to the characteristic background spectrum, indicating that, within the sensitivity of the instrument, no other crystal phases were present throughout the experiment.

Microscopy imaging revealed crystals of varying sizes, with larger crystals tending to appear later in aging. Crystals around $5 \mu \mathrm{m}$ in size were observed in all rind samples starting on d 10 (Figure 9A), with slightly larger crystals observed in the rind by d 14 (Figure 9B) and crystals up to $20 \mu \mathrm{m}$ observed in the rind by $\mathrm{d} 18$ (Figure 9C).

\section{DISCUSSION}

\section{Extent of pH Gradient Development}

By the end of the 18-d observation period, a $\mathrm{pH}$ gradient of approximately $0.7 \mathrm{pH}$ units had developed between the center and rind of the wheel. The gradi-

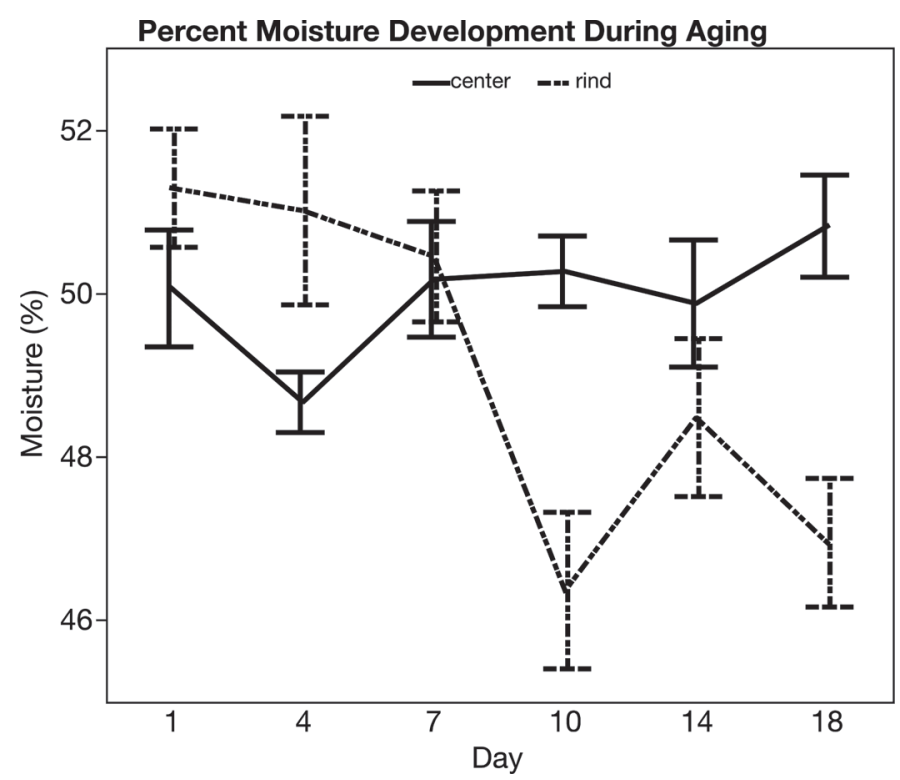

Figure 7. Average percent moisture of rind and center sampling locations during aging. Error bars represent Se from all 3 batches and duplicate cheeses on each sampling day.
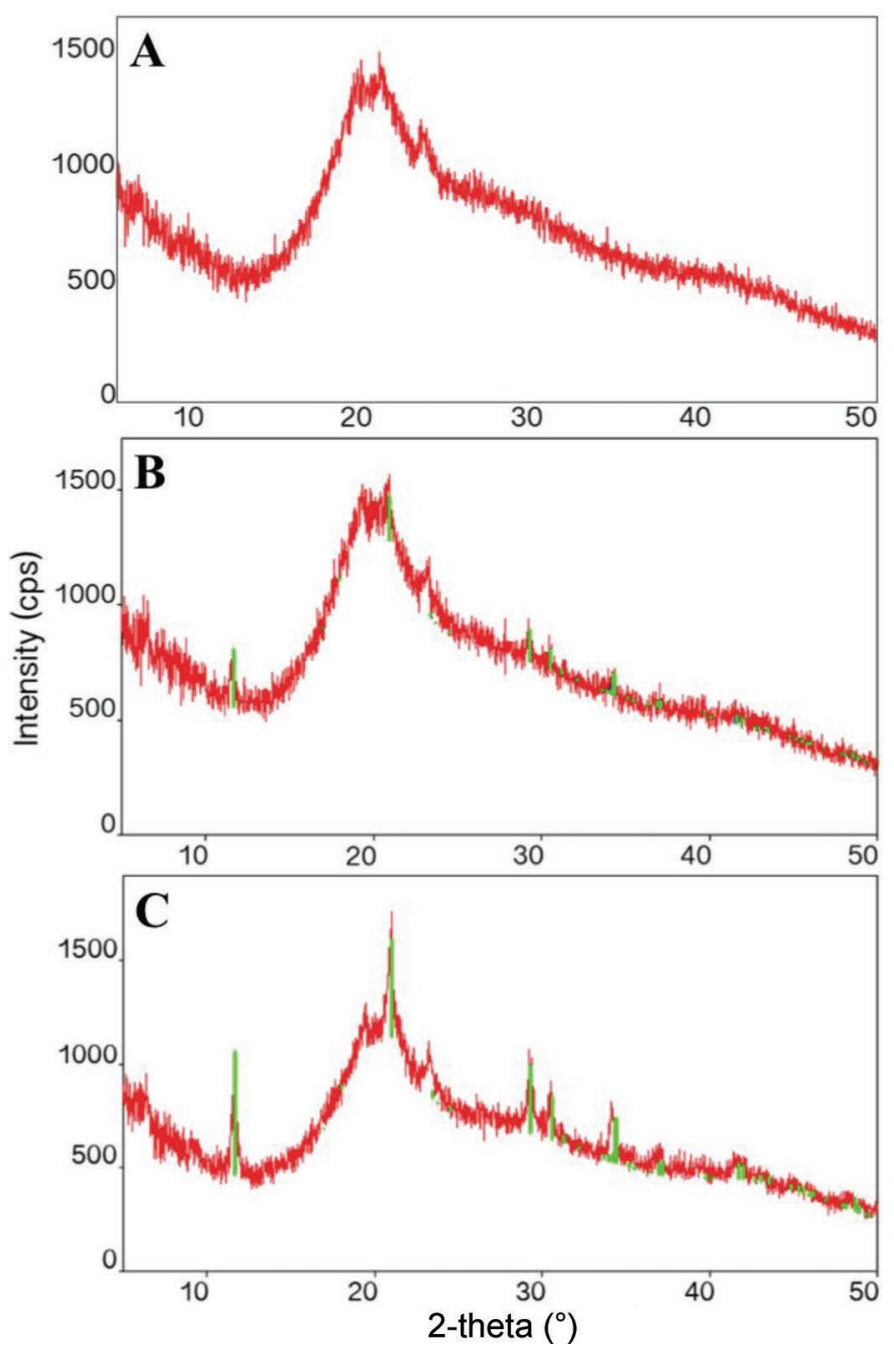

Figure 8. Examples of powder x-ray diffractograms of the rind on (A) d 1, (B) 10 (figure of merit: 1.104), and (C) 18 (figure of merit: $0.770)$. Vertical bars represent the reference diffraction pattern for brushite $\left(\mathrm{CaHPO}_{4} \cdot 2 \mathrm{H}_{2} \mathrm{O}\right.$, International Center for Diffraction Data card \# 01-075-4365). cps = counts per second. Color version available online.

ent began to appear after $\mathrm{d} 10$ and was a result of a $\mathrm{pH}$ increase at the rind as well as a $\mathrm{pH}$ decrease at the center. The decreased $\mathrm{pH}$ at the center was likely caused by continued fermentation of residual lactose by the starter cultures, which can happen at the center while salt levels are low (Lawrence et al., 1987) and until the salt has diffused sufficiently from the surface to the center.

From $\mathrm{d} 7$ to 18 the $\mathrm{pH}$ at the rind steadily increased, with the greatest increase occurring between $\mathrm{d} 7$ and 14. The increase was likely caused by the fungal consumption of lactic acid and production of ammonia (Amrane and Prigent, 2008), although neither of these parameters were measured in the present study. The 

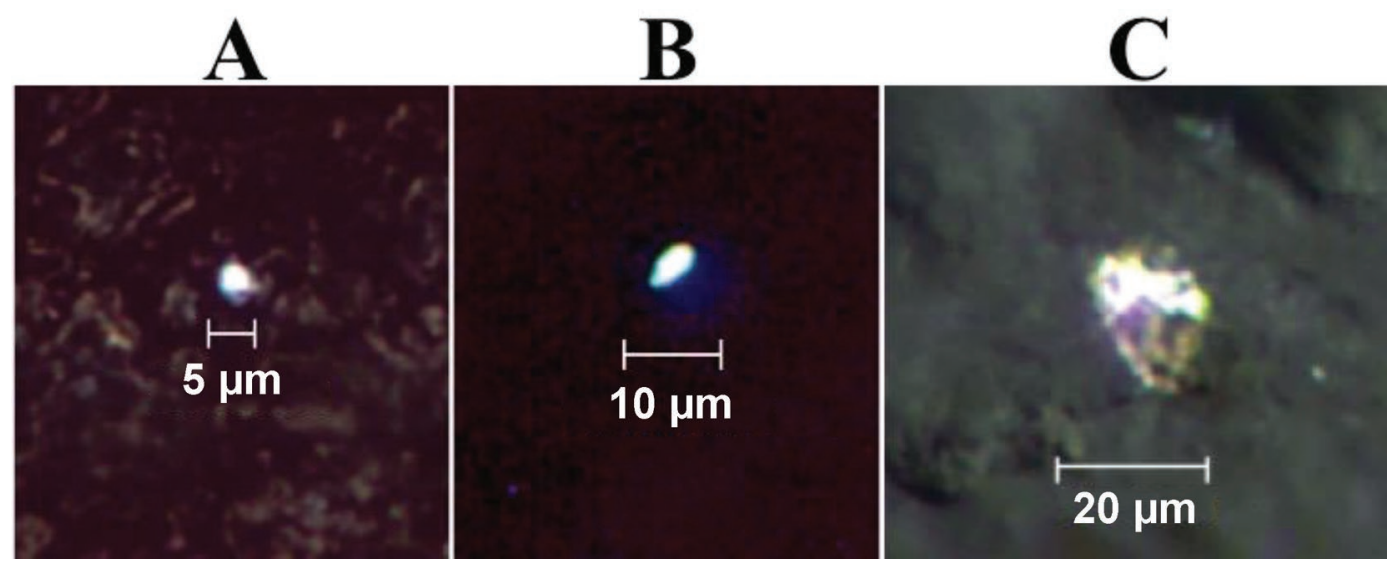

Figure 9. Examples of micrographs displaying crystals on d 10 (A), 14 (B), and 18 (C) rind samples. Color version available online.

decreased rate of alkalinization between d 14 and 18 likely reflects the typical decrease in metabolic activity that accompanies a decrease in temperature, as the cheeses were placed in cold storage on d 14 .

Compared with the observations of previous investigators (Le Graet et al., 1983; Karahadian and Lindsay, 1987; Le Graet and Brule, 1988), who used traditional Camembert or Brie as their subjects, the $\mathrm{pH}$ gradient that developed in the present study was quite modest. Previous studies observed $\mathrm{pH}$ gradients that ranged from approximately 4.6 at the center to approximately 7 at the rind over the same aging period as the present study. In contrast, the stabilized technology of the cheese used in the present study appears to retard rind alkalinization. This could be related to the higher buffering capacity associated with greater calcium and phosphate retention in curd at elevated $\mathrm{pH}$ (Lucey and Fox, 1993), or could be related to factors that limit lactic acid consumption or ammonia production. Further investigation, including measurement of lactic acid and ammonia concentrations in the rind of stabilized cheese during aging, would be needed to elucidate the factors that control rind $\mathrm{pH}$ in this variety and in other stabilized white mold cheeses.

\section{Moisture Development During Aging}

The observed retention of moisture at the cheese center in the present study contrasts with the work of Leclercq-Perlat et al. (2012), who observed that the center of traditional Camembert-type cheese lost moisture over approximately the same timeframe as the present study. Those findings confirmed the observations of Le Graet et al. (1983), who noted an increase in DM content at the center of traditional Camembert during aging. It should be noted that the stabilizedstyle cheese in the present study had a considerably lower initial moisture content than the traditional white mold cheeses used in the aforementioned studies. Differences in the humidity and airflow in the ripening chamber are known to affect the rate of moisture loss (Leclercq-Perlat et al., 2012), and it is likely that curd characteristics, as well as cheese dimensions, influence moisture retention as well. Further studies on stabilized white mold cheese are needed to determine if this moisture pattern is characteristic of stabilized white mold cheese or is an artifact of the sampling methods.

\section{Significance of Brushite Crystallization}

Brushite solubility is influenced by $\mathrm{pH}$, and under acidic conditions it is quite soluble; however, as the $\mathrm{pH}$ tends toward neutrality, the solubility of brushite decreases by several degrees of magnitude (Johnsson and Nancollas, 1992). Under moderately acidic conditions, brushite is the least-soluble calcium phosphate phase, but as the $\mathrm{pH}$ increases other calcium phosphate phases, such as hydroxylapatite, eventually become less soluble than brushite (Ferreira et al., 2003). Over the $\mathrm{pH}$ environment that may be found in both stabilized and traditional white mold cheeses (roughly 4.6 to 7), brushite is less thermodynamically stable than hydroxylapatite, tricalcium phosphate, and octacalcium phosphate, although kinetic factors may result in the preferential formation of brushite (Johnsson and Nancollas, 1992). Thus, even though brushite is not the most thermodynamically stable calcium phosphate phase, the appearance of brushite in the present study at a $\mathrm{pH}$ between 5.3 and 5.6 is not precluded.

As stated previously, the $\mathrm{pH}$ of the rinds of traditional Camembert-style cheeses that were investigated by other workers climbed to around 7 . At this $\mathrm{pH}$ the solubilities of other calcium phosphates are much lower than that of brushite (Johnsson and Nancollas, 1992), 
and the possibility of other calcium phosphate phases crystalizing in the rind is likewise increased. Thus, the elevated ratios of calcium to phosphorus that were found by other investigators could reflect phase transitions that can occur at elevated $\mathrm{pH}$. Using electron microscopy, Brooker (1987) described 2 distinct morphologies of crystals in the rind of Coulommiers cheese, and these could potentially represent 2 co-occurring calcium phosphate phases. Therefore, it may be fruitful to apply PXRD to the study of traditional white mold cheeses to determine if phases other than brushite appear as a function of elevated rind $\mathrm{pH}$.

In the present study, the molar increases in calcium and phosphorus in the rind, corrected for the initial quantities of those elements on $\mathrm{d} 1$, were not statistically different throughout aging $(P=0.048)$, which conforms to the 1:1 molar ratio of calcium to phosphorus in brushite. However, these data alone would not necessarily lead to the conclusion that the crystal phase in the present study was brushite. Several calcium phosphate phases contain stoichiometric equivalents of calcium and phosphorus; thus, any of these phases could account for the observed accumulation of calcium and phosphate in the rind. Similarly, based on their elemental analysis of a model cheese system containing crystals, Amrane and Prigent (2008) proposed that the crystals were dicalcium phosphate, which is a term that encompasses several crystal phases containing the unit $\mathrm{CaHPO}_{4}$, including brushite. In their study, as well as in the present study, the particular crystal phase could not be precisely determined from elemental analyses alone.

In the present study, when the uncorrected molar quantities of calcium and phosphorus were compared, we found a statistically significant $(P<0.0001)$ excess of calcium in the rind throughout aging. In the absence of a crystallographic technique, the uncorrected data could have led one to believe that a crystal phase or several different crystal phases containing a higher proportion of calcium to phosphorus was present. It should be noted that the data in the present study cannot explain the excess of calcium in the rind. Nonetheless, these data may be used to demonstrate the potential pitfalls of using elemental analysis to indirectly identify crystal phases in cheese rinds.

\section{Accumulation of Mineral Elements in the Rind}

Starting on d 10, we noted a steady accumulation of calcium, phosphorus, and magnesium in the rind that tapered off between d 14 and 18. This closely correlated with the degree of increase in rind $\mathrm{pH}$ during the same period of aging (Table 2), which suggests a link between the rate of $\mathrm{pH}$ elevation and the rate of brushite crystallization. The latter point seems to imply that brushite in the present study was only slightly supersaturated at the range of rind $\mathrm{pH}$, because as the increase in rind $\mathrm{pH}$ slowed so did the rate of calcium, phosphorus, and magnesium accumulation in the rind.

Calcium and phosphorus accumulation could be easily attributed to brushite, which contains both elements in its chemical formula $\left(\mathrm{CaHPO}_{4} \cdot 2 \mathrm{H}_{2} \mathrm{O}\right)$. Even though the chemical formula does not include magnesium, elemental analysis indicated that magnesium accumulated in the rind as well. The mass of magnesium that deposited in the rind was very small compared with calcium and almost certainly deposited in calcium sites in the brushite lattice. Magnesium and calcium are both alkaline earth elements, and due to magnesium's smaller atomic radius magnesium may substitute for calcium in the brushite crystal lattice (Lee and Kumta, 2010). Further studies are necessary to confirm this assumption, because diffractograms of moderately substituted brushite cannot be distinguished from pure brushite; therefore, the diffractograms in the present study cannot be used to verify this premise.

\section{Cheese Demineralization}

The results of our study demonstrate that a mineral element diffusion phenomenon occurs in stabilized white mold cheese that had not been previously observed. The processes of brushite crystallization and concurrent calcium, phosphate, and magnesium diffusion result in a significant reduction of calcium, phosphate, and magnesium in the center of the wheel by the end of the study. By the final day of observation, the center of the cheese contained, on average, $26.4 \%$ less calcium, $14.8 \%$ less phosphorus, and $12.1 \%$ less magnesium. On a molar basis, the calcium content at the center was reduced by approximately twice that of phosphorus. This may reflect the slower diffusion of phosphorus in the cheese matrix due to its larger ionic radius. Further investigations that include measurements of phosphorus and calcium at intermediate points between the rind and the center are needed to fully explain how the concentration of calcium at the center can decrease more extensively than the concentration of phosphorus. Nonetheless, these observations suggest that the diffusion of mineral elements may be a complex process that warrants additional study.

The diminished concentrations of these elements, and especially the reduction in calcium, is potentially important from a cheese technology standpoint, given the significance attributed to calcium in casein-casein interactions and casein hydration (Feeney et al., 2002). Although the concentration of calcium in the cheese center at the end of the present study was higher than 
the concentration previously reported for traditional Camembert over the same aging time (Le Graet et al., 1983), the demineralization observed in the present study is still noteworthy. Further research is necessary to determine if demineralization in stabilized white mold cheese has an effect on the texture of the ripened cheese.

\section{CONCLUSIONS}

The process of rind alkalinization and cheese demineralization that had been previously observed in traditional white mold cheese was observed in a limited form in a stabilized white mold cheese. A relatively small pH gradient developed between the rind and center of the cheese, which was accompanied by a significant diffusion of calcium, phosphorus, and magnesium from the center to the rind. Crystallographic techniques aided in determining that brushite crystals precipitated in the rind and were responsible for the accumulation of mineral elements in the rind. Further research is necessary to determine the role that demineralization plays in texture development of stabilized white mold cheese. Studies designed to investigate the effect of modulating the degree of demineralization, while holding the $\mathrm{pH}$ constant, could provide great insight into the role that calcium concentration plays in texture characteristics of stabilized white mold cheese and cheese universally.

\section{ACKNOWLEDGMENTS}

This study was funded by United States Department of Agriculture Hatch Project VT- H02102. The National Science Foundation is gratefully acknowledged through support of grant EAR-0922961 for the purchase of the x-ray diffractometer. The Cellars at Jasper Hill is also gratefully acknowledged for supplying the cheeses used in this study.

\section{REFERENCES}

Amrane, A., and Y. Prigent. 2008. Diffusion of calcium and inorganic phosphate at the surface of a solid model medium in relation with growth of Geotrichum candidum and Penecillium camembertii. J. Food Biochem. 32:813-825.
Boutrou, R., F. Gaucheron, M. Piot, F. Michel, J. Maubois, and J. Leonil. 1999. Changes in the composition of juice expressed from Camembert cheese during ripening. Lait 79:503-513.

Brooker, B. E. 1987. The crystallization of calcium phosphate at the surface of mould-ripened cheeses. Food Struct. 6:25-33.

EPA. 2012. Determination of metals and trace elements in water and wastes by inductively coupled plasma-atomic emission spectrometry method 200.7. 40CFR part 136. Fed. Regist. 77:29813 (Water Programs, Environmental Protection Agency, Washington, DC.).

Feeney, E. P., T. P. Guinee, and P. F. Fox. 2002. Effect of $\mathrm{pH}$ and calcium concentration on proteolysis in mozzarella cheese. J. Dairy Sci. 85:1646-1654.

Ferreira, A., C. Oliveira, and F. Rocha. 2003. The different phases in the precipitation of dicalcium phosphate dihydrate. J. Cryst. Growth 252:599-611.

Gaucheron, F., Y. Le Graet, F. Michel, V. Briard, and M. Piot. 1999. Evolution of various salt concentrations in the moisture and in the outer layer and centre of a model cheese during its brining and storage in an ammoniacal atmosphere. Lait 79:553-566.

Johnsson, M. S. A., and G. H. Nancollas. 1992. The role of brushite and octacalcium phosphate in apatite formation. Crit. Rev. Oral Biol. Med. 3:61-82.

Karahadian, C., and R. C. Lindsay. 1987. Integrated rales of lactate, ammonia, and calcium in texture development of mold surfaceripened cheese. J. Dairy Sci. 70:909-918.

Kosikowski, F. V., and V. V. Mistry. 1997. Cheese and Fermented Milk Foods. Vol. 1. F.V. Kosikowski, Great Falls, VA.

Lawrence, R. C., L. K. Creamer, and J. Gilles. 1987. Texture development during cheese ripening. J. Dairy Sci. 70:1748-1760.

Le Graet, Y., and G. Brule. 1988. Migration des macro et oligo-éléments dans un fromage à pâte molle de type Camembert. Lait 68:219-234.

Le Graet, Y., A. Lepienne, G. Brule, and P. Ducruet. 1983. Migration du calcium et des phosphates inorganiques dans les fromages à pâte molle de type Camembert au cours de l'affinage. Lait 63:317-332.

Leclercq-Perlat, M. N., M. Sicard, I. C. Trelea, D. Picque, and G. Corrieu. 2012. Temperature and relative humidity influence the microbial and physicochemical characteristics of Camembert-type cheese ripening. J. Dairy Sci. 95:4666-4682.

Lee, D., and P. N. Kumta. 2010. Chemical synthesis and stabilization of magnesium substituted brushite. Mater. Sci. Eng. C 30:934-943.

Lucey, J. A., and P. F. Fox. 1993. Importance of calcium and phosphate in cheese manufacture: A review. J. Dairy Sci. 76:1714-1724.

Metche, M., and J. Fanni. 1978. Rôle de la flore fongique dans l'accumulation du calcium et du phosphore à la surface des fromages du type camembert. Lait 58:336-354.

Noomen, A. 1983. The role of the surface flora in the softening of cheeses with a low initial pH. Neth. Milk Dairy J. 37:229-232.

Tansman, G. F., P. S. Kindstedt, and J. M. Hughes. 2014. Powder $\mathrm{x}$-ray diffraction can differentiate between enantiomeric variants of calcium lactate pentahydrate crystal in cheese. J. Dairy Sci. 97:7354-7362.

Vassal, L., V. Monnet, D. Le Bars, C. Roux, and J. C. Gripon. 1986. Relation entre le $\mathrm{pH}$, la composition chimique et la texture des fromages de type Camembert. Lait 66:341-351. 